\title{
How do Children become Workers? Making Sense of Conflicting Accounts of Cultural Transmission in Anthropology and Psychology
}

Christopher A. J. L. Little and David F. Lancy

Running Head: Making Sense of Cultural Transmission

Christopher A. J. L. Little is Post-Doctoral Fellow at York University

David F. Lancy is Emeritus Professor of Anthropology at Utah State University

Lead Author Contact Information:

littlech@yorku.ca 
As documented in the previous articles in this Special Issue, children's work offers rich scope for analyzing child-rearing and development. However, scholars remain divided between two positions with regards to cultural transmission and the processes underlying children's learning of domestic and subsistence skills. The first perspective, associated with studies which draw upon ethnographic data, places the burden of skill (e.g., gardening, hunting, weaving) acquisition on the child who "picks up" skills and ideas through exploration, careful observation, imitation, various types of play, interaction with peers, participation with others in carrying out routine tasks and other voluntary, self-initiated activities (e.g., Lancy 2010; Mead 1964; Rogoff 2008). From this perspective, the child certainly looks at parents and other experts as role models and worthy of imitation ${ }^{1}$, but not necessarily as teachers. A second position, that is associated with studies which draw heavily upon interview data, assigns great importance to parents as teachers who transmit essential skills and knowledge to their children (e.g., Hewlett and CavalliSforza 1986; Kline, Boyd, and Henrich 2013). The elevation of teaching to a critical role in the transmission of vital skills and information in this model is, in contrast to the longstanding ethnographic emphasis upon self-initiated learning, a more recent trend (Kline 2015).

This article uses children's work as a lens to examine methodological concerns in the study of cultural transmission and children's learning of useful domestic and subsistence skills. We begin by providing a review of the relevant literature concerning cultural transmission in the context of the ethnographic record, as well as more recent studies originating largely from psychology. We then offer an ethnographic case study concerning Asabano (PNG [Papua New Guinea]) childhood to make an important methodological contribution in the interdisciplinary study of cultural transmission. The case study centers on the paradox that Asabano parents, in interviews, claim that their children learn almost exclusively via parental teaching. Field observation and the parent's and children's spontaneous remarks suggest that this, in fact, does not happen and that children are expected to learn largely on their own with little parental 
intervention. To account for this paradox, we illustrate the limits of asking in particular cultural contexts like that of the Asabano, as well as the influence of institutions such as schools and churches, which have provided new and influential models of teaching that interlocutors are able to refer to in the context of interviews without necessarily changing their actual practices.

Cumulatively, we illustrate that conflicting scholarly perspectives regarding cultural transmission and children's learning of domestic skills may not be a strictly empirical matter. Instead, these perspectives appear to be derived from the contrasting methodologies that are largely associated with different disciplines: subject interviews and heavy reliance on contemporary western data sources in psychology, and ethnography, including extensive observation and as well as ethnographically and historically ${ }^{2}$ informed interviews in anthropology. This article does not simply problematize the use of the interview in studies of cultural transmission. Instead, we problematize the sole reliance upon decontextualized selfreport data and call for interviews to be situated within an ethnographic framework which not only involves observations, but also considers local cultural models of cultural transmission, local communicative norms and practices, and social histories which accounts for socio-cultural change.

\section{The Role of Teaching versus Self-initiated, Self-guided Learning in Skill}

\section{Acquisition}

There are several comprehensive models proposed to account for the most likely means by which children become competent members of their families and communities. These include the LOPI (Learning by Observing and Pitching In cf. Rogoff 2014) model, in which children learn by both passive observation and participation in joint work activities (see the introduction 
to this volume). In contrast, Konner (2010:719) has argued for the existence of a CAD (Culture Acquisition Device), which is composed of 20 distinct processes divided into four categories that make children uniquely prepared to learn from their environments. Lastly, another recent model is Csibra and Gergely's (2009) "Natural Pedagogy," which holds that human communication is specifically adapted to allow the vertical transmission of opaque knowledge and skill.

Our goal in this article is more modest than presenting a comprehensive model to account for the way in which children learn skills. Rather, we attempt to gauge the relative roles of teaching versus self-initiated, self-guided learning that scholars assign to children's skill acquisition. We illustrate how the lines in an emerging debate are very clearly drawn (Bonawitz et al. 2011). Further, we will show how there is a close relationship between these opposing positions and the methodological tools employed in the studies which undergird these positions.

On the one hand, anthropologists who have considered the issue have maintained an enduring consensus that much of cultural transmission is the result of observation and everyday activities rather than intentional pedagogy. In their Children of Six Cultures Study, the Whitings, for instance, conclude that,

...skills are more likely to come from observation than from instruction. It should not be assumed that parents play an entirely passive role in the socialization process. It is in the assignment of tasks and the punishment of disobedience rather than...deliberate instruction or rewarding and punishing specific behaviors that they [i.e., parents] have the greatest effect (B.B. Whiting and J. M. W. Whiting 1975:180).

Lave (1988:14), similarly writes that, "everyday activity...is a more powerful source of socialization than intentional pedagogy," and Atran and Sperber (1991:39) note that, "In most human societies, children become competent adults without the help of....teaching 
...Most learning is achieved as a by-product, in the course of interactions that have other purposes." In fact, anthropologists as well as primatologists studying juveniles often draw marked attention in their ethnographic/field accounts to the almost total absence of teaching of juveniles by their parents or others (Lancy 2010; Lancy and Grove $2011^{3}$ ). More emphatically, there are many cases where anthropologists record the explicit rejection of teaching by child and adult informants (Arnold 2006:121-2; Howell 1988:162; Raum 1940:246-67). While numerous other sources point to nearly identical conclusions (e.g. Langdon 2013:174), our point is to illustrate the consistency with which scholars, often anthropologists with extensive ethnographic experience, have concluded that teaching appears to be of secondary importance relative to self-directed learning initiated by children.

In contrast to the longstanding ethnographic emphasis placed upon children as selfinitiating learners, a more recent trend in scholarship has seen teaching elevated to playing a critical role in the transmission of vital skills and information to developing children, while simultaneously insuring the preservation of the culture (Kline 2015). As examples of this position, Strauss and Ziv (2004:451), for instance, speak of the "the centrality of adult teaching in educating children and in enhancing their cognitive development," while Goldman and Booker (2009:370) similarly note that, "parents are the primary, most committed and effective educators of their children." Kruger and Tomasello (1996:377) deploy the concept of "guided learning" to refer to an explicit process involving the teaching of children by adults who have a uniquely human “pedagogic disposition.” Lastly, Gergely et al. $(2007: 139,145)$ advance the "specific social learning system called 'pedagogy"” to refer to a specific human adaptation to understanding the spontaneous human tendency to transfer cultural information to conspecifics.

While the above statements seem to indicate significant differences, both perspectives may ultimately capture cultural practices employed in preparing children for adulthood, but 
neither applies universally. Teaching is de rigueur in urbanized, post-industrial middle-class communities both for learning in school and at home. The LOPI model, for example, does not apply in these contexts because these children have little opportunity to observe, let alone practice adult skills in the context of actual work (Dunn 1988:309). In the societies historically studied by anthropologists, as well as the ethnic and class-based subcultures found in developed nations, child-initiated learning may be paramount, and teaching rare. However, with increasing globalization and Westernization, there appears to be a gradual shift to the more "modern," or academic "educational" practices that depend on extensive verbal interaction between children and their teachers.

After all, as shown in numerous studies across from across the non-western world, "women internalize the teacher role from their experience in Western-type schools and use it as mothers" (LeVine et al. 2012:139). Rogoff and colleagues have authored several studies contrasting learning processes in "indigenous" or traditional Mayan communities with those nearby that had experienced a longer and more intense history of schooling and modernization (Rogoff et al. 2005) with predictable results: in the latter communities, children expect to be taught and parents expect to teach. In a second line of research, Rogoff et al. (2014) gathered archived data from three generations of research in a small rural region of Guatemala and showed how children's autonomous learning in the community gradually gives way to adult managed and instructed learning.

As we will illustrate below, there is reason to believe that schooling may not only influence parental behavior, but also their responses in interviews. Such broad, global transitions (Garcia et al. 2015), and the way in which they are articulated in diverse cultural settings, point to important questions about the way in which cultural transmission is now conceptualized amongst these populations. Similarly, for scholars of cultural transmission, these transitions raise important methodological questions concerning the way in which cultural transmission can now 
be studied amongst populations where western schooling may not only alter local cultural practices in various ways, but also provide people with new models of cultural transmission.

\section{Teaching and the Role of Interviews in Studying Cultural Transmission}

As illustrated above, one group of scholars' descriptions of the social learning process assigns a very minor role for teaching in cultural transmission, especially with respect to "learning one's chores," while another group claims that teaching is ubiquitous and critical—-that all parents are able and willing teachers and all children are willing and able students (see also Lancy in pressb). While the work of Rogoff and colleagues suggests that these discrepancies may be a result of large scales trends in which populations gain increasing experience with schooling and begin to adopt a western model of teaching, we suggest that findings indicating frequent and extensive parental instruction may also be heavily skewed by the nature of the methodology employed.

Scholars have studied cultural transmission through a variety of methodological approaches. In addition to lab experiments (Tomasello 2001), computer modeling (Strimling et al. 2009), and ethnography (Lancy 1996), there have been several important studies of cultural transmission supported primarily by interview data. However, studies that rely exclusively on self-report interview data may be plagued by significant problems. In fact, interview data seem particularly limiting in trying to untangle the very complex processes involved in cultural transmission.

In one widely cited study, the authors reported on the results of an interview survey of the distribution of 50 distinct and common skills among the Aka-forest foragers from central 
Africa. The sample consisted of 40 adults, 16 children aged seven-to-twelve and 16 unmarried adolescents. When asked to recall who had shown them how to perform a skill, 81 percent of respondents identified a parent (Hewlett and Cavalli-Sforza 1986). The impression conveyed (and taken for granted by those citing the study) by the author's discussion of the Aka data is that cultural transmission occurs largely by parents teaching their children. However, the authors do not clearly differentiate between adult-directed, explicit, intentional teaching and more informal, learner-initiated emulation of an older role model, or the kind of interactive transmission of knowledge and skill that occurs during the participatory activity described by Lave, Rogoff and colleagues (Lave and Wenger 1991:55; Rogoff et al. 2003:178).

Similarly, in a survey of craft skill transmission among the Maya, Hayden and Cannon (1984) also suggest that teaching is predominant, yet problematically, the authors had eliminated from their analysis anyone who claimed to have learned without a teacher and "in cases of selfteaching where individuals also indicated that their parents knew specific crafts, we assumed that they learned from their parents" (Hayden and Cannon 1984:343). The authors had clearly assumed the centrality of vertical transmission via teaching, without actually documenting it. Lastly, in a more recent interview study conducted with Fijian adults, the authors found evidence for the significant role played by teaching. Yet, depending on how the query was posed, teaching was seen as critical in the transmission of valued skills 18 percent to 43 percent of the time (Kline et al. 2013). In addition to isolating their study of cultural transmission to domains which they believed were more likely to be transmitted by teaching, this study illustrates how even relatively simple factors, such as the way in which questions are posed, can dramatically impact findings.

Cultural change and exposure to schooling may also be a significant unaccounted for factor influencing the results of interview studies. In a replication of the earlier Aka study carried out on a small Fijian island, parents claimed to do a great deal of teaching. While the interviews 
are very carefully constructed, the authors do not provide any descriptions of parents actually teaching to rule out the kind of response compliance recorded for the Asabano (see below). The interviewees had had over 100 years' exposure to Western schooling (all interviewees had completed primary school and some had gone to secondary school) and missionary influence (Kline et al. 2013:357). The fact that interview questions_-in which researchers asked respondents how, from whom, and at what age children acquire particular skills---were readily interpretable reinforces a sense that respondents had significant experience with western models of teaching derived from schooling. Likewise, an earlier study by this research group in the same community found that years of schooling was negatively related to perceived knowledge of traditional subsistence practices (Henrich and Broesch 2011:1145), suggesting an unaccounted for influence of schools in their work. While schooling may lead to the loss of IKS (Indigenous Knowledge Systems, Urrieta 2016), these findings also indicate how schooling makes available a model of western teaching which respondents are able to refer to in the context of interviews. That is to say, respondents may be altering their behaviors, but they may also be altering their responses without any corresponding modification of their actions, as in the case of the Asabano (see below).

Others who have studied craft skill acquisition see a more varied and complex picture of the process and have pointed to methodological problems in studying children's learning (Lancy 2012). In reviewing a number of studies which appear to provide evidence for the role of teaching in craft production, Gosselain, for instance, suggests that:

Parent-to-offspring accounts of transmission could be partially fictional, a research artifact due perhaps to an over-reliance on interviews during fieldwork, some preconceptions about craft learning in informal contexts, and the emphasis put by the 
artisans themselves on 'tradition' and 'heritage,' especially when confronted by foreigners (Gosselain 2008:153).

Gosselain points to the multifaceted problem of researchers actually studying teaching in the process of cultural transmission. Likewise, he also calls for the need for closer readings of those studies which may seemingly point to the importance of teaching, yet in fact display problems in study design and analysis, and ultimately do not support such a position.

Focusing on studies that depend primarily on observational data or a combination of observation and interview — that is, ethnography_yield much lower estimates of the prevalence of teaching (Lancy 2010, 2015; Lancy and Grove 2011). In more quantitative analyses of field data this conclusion is reinforced. In contrast to Hayden and Cannon's (1984) problematic finding that teaching predominates, Rogoff reports of the Highland Maya: "of the 1708 observations of nine-year-olds, native observers could identify only six occasions as teaching situations" (Rogoff 1981:32). Similarly, after viewing hundreds of hours of ethnographic film shot among !Kung and Netsilik (Inuit) foraging bands, Bruner was struck by the total absence of teaching episodes (1966:59). Likewise, Odden and Rochat conducted a two-year ethnographic study with systematic observation and interviewing to ascertain how specific realms of culture are transmitted on Samoa, including very important maritime subsistence skills such as throw-net fishing. They conclude that: "Samoan children acquire a range of skills and understandings [including] subsistence activities...without the active assistance of more experienced social others" (Odden and Rochat 2004:47; for comparable results, see Vermonden 2009:205). In contrast to the near universal claim by Samoan parents made during interviews that children learn through being taught by others (Odden 2007:214), Odden observed, as an example, multigeneration fishing parties on 50 occasions, ranging from one-three hours in length, and only once noted an adult supervising and guiding a child fisher (Odden 2007:220). 
More recent studies of the same Aka foraging community have produced findings which cast doubt upon Hewlett and Cavalli-Sforza's (1986) study in which the authors used interviews to support the conclusion that teaching was predominant. Relying upon ethnographic observation, rather than interviews, Hewlett and colleagues (2011:1173; Hewlett and Hewlett 2013:76; Bonnie Hewlett 2013:67-68) present evidence of how and from whom children learn. Their findings, including that "teaching is relatively rare by comparison to observation and imitation" (Hewlett et al. 2011:1176), are more consistent with the ethnographic record as a whole. Likewise, in a report drawing on two systematic observational studies, Boyette (2013:91) — using a much broader, more inclusive definition of teaching than we do (see the introduction to this volume) — finds teaching to be quite rare among the Aka.

\section{Cultural Transmission amongst the Asabano}

The extent to which the methods researchers employ influence the model of skill acquisition that emerges from the study, as well as the influence of western institutions such as schools and churches, will be forcibly brought home in the following case study. The study draws upon data collected amongst the Asabano, a relatively remote ethno-linguistic group of 300 persons who live in several hamlets scattered around the Telefolmin District of PNG's West Sepik Province. Asabano experienced "first contact" with the colonial government in 1963 and are therefore amongst the last populations to be incorporated into the state. Due to their small size, as well as their distance from urban centers and large-scale resource extraction projects, Asabano reside in an extremely rugged environment with only minimal interventions and support from the state. This study illustrates now only the danger of relying exclusively on interview data and the need to consider historical forces in shaping responses to queries regarding cultural transmission. 
As part of a broader study concerning indigenous practices of cultural transmission, both children and adults were verbally surveyed about their experiences as teachers and learners. While scholars have called for increased attention to, and the direct inclusion of, “children's voices" (e.g., Prout 2003; Qvortrup 1990) in social research, as other ethnographers have found (e.g., Chapin 2014:13-14), children were unaccustomed to the question and answer sequences typical of formal interviews (see also Ninnes 1995:23). In this study, many children quickly grew uncomfortable when subjected to questioning and rapidly departed from the interview area. While children were at times willing to respond to queries, this was only so long as questions were posed in the context of naturally occurring activities.

Adults $(\mathrm{N}=15)$, in contrast to children, were enthusiastic participants in interviews. With regards to how children learned, adults vigorously emphasized their active role as teachers of children. Adults described virtually all the knowledge that children possessed, whether about subsistence skills, witches, or appropriate behavior, as resulting from explicit parental instruction. To adults, the notion that children could potentially learn without their direct intervention seemed unfathomable. When asked about specific subsistence activities, for example, interlocutors almost always recited general statements, such as "I taught him/her" (mi lainim em). Likewise, they often excitedly attempted to mimetically illustrate themselves performing particular tasks that they taught to their children. When asked how his adult children had learned to garden, for instance, a senior man named Steven explained proudly that "I taught them" and then began to illustrate how. Grabbing an imaginary digging stick, he motioned as if to make holes in the garden soil, into which he then inserted imaginary sweet potato vines, explaining that he told the children who stood by observing him to "do it like I'm doing it" (wokim olsame mi).

Similarly, when adults were asked how they had learned a particular skill as children, they pointed to a parent or primary caregiver who had taught them, much as they now described 
themselves teaching their own children. Mandex, a middle-aged man and father of three young children, for instance, explained that he had learned how to carve arrows in the same way which his son, Jim, learned. As he explained it, "my father taught me and I taught Jim." Similarly, Anna, a mother of several children and expert string bag (bilum) manufacturer explained how she wanted to learn to produce a new style of string bag, but was unable to do so because she had not been taught. To learn the new style, she and other senior women had organized a group so that younger women who had travelled outside the village would be able to "teach the mothers" (lainim ol mama).

This interview data collected from adults that pointed to the importance of direct teaching by adults in skill acquisition, however, seemed to conflict with data collected outside of interviews. For instance, while adults cited themselves as being centrally important to the processes of children's skill acquisition, as in the examples above, the few children who made statements about how they had learned some particular skill cited themselves as the source of their skill, or others whom they had observed and imitated. For example, whereas Mandex stated that he taught his son Jim to carve rudimentary arrowheads, Jim suggested that he had learned to carve arrowheads himself through trial and error, while he also occasionally spent time silently observing elder men who carved arrows to pass the time.

Likewise, while adult interlocutors professed to teach their children in the context of interviews, in naturally occurring settings they often spoke to the very impossibility of this same thing. Indeed, in informal contexts, they often stated that children were, by their very nature, "unable to listen" (no inap harim) or "unable to understand" (no inap long save) the instructions of adults. This perspective - that is, parental ethnotheories that suggest that children cannot be taught by adults - is widely reported in the ethnographic literature (Lancy 2015). For example, as one mother impatiently explained as her 2-year old daughter played with a knife, intervention to modify her daughter's behavior was pointless because the girl would simply ignore her 
instructions and do as she pleased. Further still, in some cases, adults would act to obstruct children's voluntary attempts to learn. For instance, when Junior, a six-year old boy, accompanied his family to the family garden and began planting corn seeds beside his two parents, rather than viewing this as a didactic opportunity, his parents shooed him away, explaining that he should go play at a distance. On another occasion, when I attempted to teach children to draw, several adults interrupted to explain that children would not understand and that this was a waste of my time.

Together, these data paint a conflicting portrait of cultural transmission amongst Asabano. In formal interviews, adults claimed that they explicitly taught their children skills, yet in the context of daily life, the same adults denied the possibility of teaching children. Likewise, while adults claimed to teach children particular subsistence skills, children themselves often cited themselves as the source of their skills, and tended to spend much of their time away from direct adult supervision. In light of these seeming anomalies, the following section explores the way in which children learn subsistence skills, using boys' development into competent hunters as a case study.

\section{Learning to Hunt}

Although both women and men engage in gardening, hunting is a subsistence activity associated exclusively with men. Feral pigs, cassowaries, and birds are important sources of food within the community, while flying foxes, birds of paradise, marsupials, and lizards provide feathers, skins, and bones that are used for tools and ceremonial goods. In addition to its practical purposes, hunting is also an enjoyable activity that provides excitement in an otherwise monotonous life, and it also confers prestige upon men who are able to distribute the highly 
valued meat. Most hunts are planned in advance, though men engage in opportunistic hunting as well and so are rarely seen without their bows and arrows when outside the village.

As is widely reported cross-culturally, childhood play mirrors the important activities which children will be expected to master as adults. It is thus unsurprising that Asabano boys devote the bulk of their play to hunting. This play can occupy significant portion of boys times for, across all sex and age groups, boys are those with the fewest constraints: they have virtually no household obligations and are instead allowed to use their time as they please. Whereas girls are constantly tending to infants, escorting their parents to gardens, or working on string bags, boys are almost always found in the presence of their bows and arrows, working on their miniature tools, discussing hunting plans, recalling stories from past hunts, or venturing out into the jungles to find birds or rats.

Boys arise early and often grab a piece of sweet potato left over from the last evening's meal, which their parents left in the warm ashes of the hearth overnight. They then take this morning meal out to public areas of the village and assemble at their informal meeting spot under some coconut trees. Here boys will wait for others to come, huddling together to keep warm in the cool morning air. As their families begin to leave their houses to engage in their tasks for the day, travelling to distant gardens or to exploit other food sources, some boys will abandon their peers to go with their families, while others remain and wait for the morning mist to clear. When the sun's rays start to cut through the clouds, producing palpable warmth, boys grab their bows and arrows and set about their work for the day. If the sun is shining particularly strongly, lizards can be found warming themselves on rocks, presenting an obvious opportunity, though the boys may crave a greater challenge and instead decide to hunt rats in the bush surrounding the village.

No matter what they choose to hunt, it is immediately evident that boys learn to hunt in the absence of their parents. Instead of learning alongside adults, boys learn to hunt both on their own through trial-and-error and within their mixed-age peer groups. On their own, boys may 
stalk lizards around the village, but they will most often practice their aim by shooting at a banana tree stump or an unripe papaya rolled along the ground.

Often, however, boys will form small groups for the purpose of hunting collectively. Group hunts generally center on one or a few senior boys who make decisions about where to go, how to proceed, and who will ultimately make the kills. Other boys tag along as enthusiastic observers and assistants, maintaining some distance behind those actively hunting. Some of these followers are competent at hunting lizards, but generally not the more difficult rats, while most are too young to hunt at all and merely join in the excitement. Those who are too young to keep pace with the group as they traverse jungle paths will stay back at the village, beginning their hunting career as every Asabano does: playing with two crossed sticks. As they age, boys who once trailed behind will take their places among peer hunters, and those who stayed behind will begin to accompany their elders and become enthusiastic observers.

To hunt, boys utilize several strategies. They favor stalking lizards, which are the only form of prey which will remain stationary as boys slowly approach. When they discover a rat's nest, they may wait nearby until the rodents venture out before launching an ambush. At other times when a nest is spotted, they may stealthily besiege the nest and launch a volley of arrows into it, hoping that it is occupied and that the arrows find a target. Lastly, they may attempt to lure rats out of their nests by scattering pieces of cooked sweet potato or some other food nearby, while they silently wait behind some brush. Regardless of the technique they employ, rats and lizards are rarely killed upon first attempt, and boys must pursue them. Lizards will only cover a few meters as they flee, but boys may have to chase rats for several minutes as they scurry through the dense cover of the jungle.

Not only do these activities occur independently of adults, but adults also do little to facilitate their hunting activities. For example, men do not generally provide bows and arrows to children. Instead, children learn to manufacture these themselves. In only one case was I aware 
of a father who provided a bow to his son, and this boy was too young to do much more than hold it. Men themselves do not manufacture their own bows - they trade for them from neighboring peoples who have access to the sturdy black palm from which they are made — and thus have little proficiency in manufacturing bows. Similarly, many men do not manufacture their own arrows and instead prefer to acquire them from one of the handful of elderly men who are expert craftsmen. Without guidance from adults, boys must manufacture their own bows and arrows, and often do so from pandanus wood and rattan fibers. Similarly, boys manufacture their arrows by carving sticks down into a sharpened point, or attaching carved and decorated, wooden arrowheads to sticks. Manufacture of these implements is often done in their groups, but boys can be seen working on their implements on their own, or occasionally, in the company of one of the elderly men who pass their last years quietly carving arrowheads.

Adults are conspicuously absent as active participants in all of these learning activities. As adult men themselves are keen hunters, it might be expected that they are anxious to pass on the necessary skills to their male children, but this is not the case. Nor are they eager to involve boys in their hunts. On their own initiative, boys sometimes accompany their fathers and older men on hunts, but this is uncommon. Although boys appear interested in accompanying their elders, men regard boys as a hindrance given the great distances they cover and the speed at which they may need to track prey (as in Medaets' account of hunting by Tapajós River men and boys, this volume, also Bird D. W. and Bliege Bird 2005:135; Boyette 2013:79; Liebenberg 1990:69-70; Marlowe 2010:157; Peters 1998:90; Reyes-Garcia 2013:208; Rival 2002:102). Likewise, hunting pigs is a dangerous activity for men, let alone boys, while cassowaries are so dangerous and elusive that they are generally taken with snares. Boys are thus most likely to observe adults hunting birds, though the hunting of these creatures differs significantly from that of other prey in that it is either done opportunistically with a slingshot, or through the use of hunting blinds. Even in the case of hunting behind blinds, boys often prove a hindrance to adult 
objectives, since they have difficulty remaining quiet and handling the tedium of spending hours sitting still, waiting for a bird to land. In the case of hunting then, the potential risks to both a successful hunt and boys themselves outweigh the potential benefits of them being involved.

Rather than directly observing men's hunting, boys are more likely to overhear stories about men's hunts. For many men, hunting adventures are some of the most exciting moments of their lives, punctuating an otherwise tedious routine. As such, these episodes constitute a main topical focus of the genre of narrative that Asabano refer to as stori (story). These narratives are told in a spirit of leisurely entertainment, often in the evenings spent around the fires. They stress adventure, danger, and are told in such a way as to build suspense and hold an audience captive. They certainly seem to play a role in fostering boys' interests in hunting, but from the perspective of novices, little useful knowledge can be extracted from these episodes since they are told for other men who already have an expert grasp of hunting technique, and instead focus upon aspects which are exciting to other adults.

From the above it is clear that boys do not acquire their hunting skills directly from men - a finding that is representative of the ethnographic record more generally. Instead, they appear to learn through several processes: observation and imitation of older, more competent boys; occasional instruction from older boys which always emerges within the context of goal directed activity (such as bow crafting); and their own experiential learning undertaken alone or, most often, among peers in the playgroup. Despite the absence of adult modeling or guidance, boys are remarkably competent hunters and routinely kill lizards, which they proudly display upon sticks, and rats, which they delight in cooking and consuming. Although boys hunt different kinds of prey than men, the important point is that they are acquiring many of the same hunting skills which adult men use: stalking, ambushing, besetting, luring, and chasing (see Bulmer 1968). This repertoire is not exhaustive, as they will master additional hunting strategies and techniques — such as driving, trapping, and the use of dogs— when they are old enough to 
begin hunting larger game with groups of young men. However, even this learning builds on skills acquired in childhood.

\section{Accounting for Competing Models: Interviewing, Personhood, and}

\section{Cultural Change}

In accounting for the competing models that emerge from both interview data drawn from adults, in which they attribute children's learning to be workers to their own teaching, as well as participant-observation data, in which children learn largely in the absence of adult intervention, we bring into relationship several factors. These include, most notably, an indigenous view of personhood that strongly influences child-rearing, and the model of childrearing that is advocated within the context of Christian churches and schools.

Like other Papua New Guinean groups (Harrison 1993:107; Kulick 1992; Stewart and Strathern 2000:29), Asabano believe that developed persons display two characteristics:

"knowledge/understanding" (save), referring to socially oriented behaviors such as sharing and respecting others' autonomy, and "will” (het), referring to more individualistic characteristics, such as assertiveness, independence, and aggression. While adults are said to possess both of these attributes in balance, children are said to display only will, and since they do not possess the capacity to learn anything other than simple information (e.g., that fire is hot), adults do not try to modify their behavior, and their wishes are almost always acceded to because adults believe they know no better. It is only as they age that children begin to show that they are developing knowledge, as evidenced by their increasingly less-selfish behavior (Little 2011). It is only at such a point that children start "getting noticed" (Lancy and Grove 2011) and adults begin subjecting children to an increasing number of social expectations. 
Although these views of human development continue to influence actual Asabano childrearing practices, they conflict with western ideas concerning child-rearing and instruction that have accompanied the Asabano conversion to Christianity and the introduction of formal schooling. Beginning in the 1970s, Asabano abandoned their indigenous ritualistic activities (e.g., Barth 1975; Jorgensen 1981; Robbins 2004) as part of a Christian revival movement that led to the founding of a local bible college. The church has been particularly important in attempting to refashion many aspects of local social life, including child-rearing. During weekly services at both Seventh Day Adventist (SDA) and Baptist churches, for example, pastors routinely devote time to instructing parents in the practice of teaching, often drawing upon biblical metaphors concerning lambs and shepherds and God and his children. Such lessons range from the need to teach children to be well behaved and "telling them not to steal," to more practical activities, such as when pastors also instruct adults about how to teach their children subsistence techniques. For instance, one pastor named Oksep demonstrated how parents ought to teach their children to plant sweet potato vines by mimicking the act of digging a hole and planting sweet potato vines and telling parishioners to tell their children to "do the same" (wokim olsame). That parents repeated and re-enacted these lessons with great verve in the contexts of interviews illustrates not only how effective pastors were in conveying these lessons, but also how the interview became a context in which adults could speak about this model, which had become linked to moral behavior.

In addition to the instruction that adults receive through their participation in churches, adults are also exposed to formal instruction through their experience with schools. Enrolling children in school has come to be seen as an important parental responsibility, advocated not only in church but by representatives of the state. As a result, most Asabano under the age of 50 have some experience of formal schooling, through which they have been exposed to a model of education that involves a formal educator, typically from large urban centers, disseminating 
information to students. Education is itself closely associated with Christianity, given the one time presence of a Baptist bible college as well as the fact that the most educated community members have trained at religious schools. Likewise, education is closely associated with modernity in its emphasis upon changing "traditional" culture, as well as the state, given that a poorly funded primary school system is virtually the only visible influence of the state in the local area. Through these associations (see also Brison 2009; Carrs and Smith 1977; Conroy 1970), school has not only exposed Asabano to this model of teaching, but also given it both great influence and legitimacy.

These tensions, between the indigenous model of child-rearing which holds that children cannot be taught, and Christianity and formal schooling that suggest both that children must be taught and provide a model for doing so, help to account for the different directions in which the data point. Such tensions manifested themselves most clearly in the context of formal interviews, which are communicative events that are largely foreign to Asabano and many other non-western groups (see also Briggs 1986). As a result, interviews conflict with a variety of local communicative norms. For example, adults rarely pose direct questions to each other except to acquire quotidian information, such that interlocutors are unused to repetitive question and answer sequences, particularly regarding serious matters. As a result, conversations with adults in naturalistic settings may be quite comfortable, but more formal scenarios characterized by direct questioning tended to make interlocutors uncomfortable. In such instances, adults often appeared to become uncertain about how to respond, or tended to fall back upon widely available statements. Cross-culturally, ethnographers consistently point to the non-verbal nature of learning, where many skills and aspects of culture never reach the level of discourse (Lancy 2010; Rogoff et al. 2003), suggesting that it would be highly unusual if persons were able to clearly articulate how to perform a certain skill, or state with clear certainty from whom, if anyone, they learned it. Likewise, as others have argued (e.g., Fiske 1997), when forced to 
respond to questions where they are unsure or do not know how to answer, interlocutors may provide answers that refer to models or theories of behavior, rather than their own actions.

As is evident in the case-study above, being able to participate in an interview is a form of skilled behavior. For instance, children, by virtue of having not attended school, are unable or unwilling to deal with the interview, while adults who have a more substantial experience of schooling and Christian teaching, are able to more actively participate in interviews. In this case, it is not simply that the introduction of schooling is altering actual cultural practices, as various authors have described (e.g., Gergely et al., 2007; LeVine et al. 2012:268), but rather that schooling also provides persons with exposure to influential models of teaching that they are then able to refer to in the context of interviews. The interview, in others words, has become more about a particular kind of performance — like the ones found in church and school—that index one as a moral, modern adult, then it is about representing transparently the kind of practices of cultural transmission that exist in everyday life. ${ }^{4}$

\section{Conclusion}

In this article, we have used the theme of children becoming competent and helpful workers to investigate methodological issues in studying cultural transmission. In reviewing the large body of literature on the subject, we have illustrated how the two primary, yet conflicting, theories concerning cultural transmission may emerge from the different research methods that scholars employ. In turn, the use of these different research methodologies tend to fall along disciplinary lines, meaning that starkly different views of cultural transmission emerge from these disciplines. Psychologists, as we showed, have tended to rely exclusively upon interviews to substantiate their theories that assign a critical role to direct, adult-managed teaching in 
cultural transmission. Conversely, anthropologists have tended to rely upon data collected through ethnographic studies, that include a mixture of observation and interview, and these scholars tend to assign a greater role to self-initiated learning by children through observation, play, and imitation.

We then further developed these points through a detailed case study drawing from a broader study of cultural transmission among the relatively remote Asabano of PNG. This brief study illustrated how different methodological instruments yielded strikingly different, and ultimately, conflicting results. Interview data with Asabano parents suggested that adults played a vital role in teaching children to be workers, and interview subjects often belabored their active participation in the process of cultural transmission. On the other hand, participant-observation data - including unsolicited verbal data emerging in naturally occurring contexts - indicated that parents displayed virtually no efforts to consciously teach children as they had described in interviews. Further still, in contexts where adults might have been expected to intervene to teach their children, such as occasions when children risked injuring themselves or others, adults often denied the very possibility of teaching or modifying their behavior, and therefore made no intervention.

We accounted for these discrepancies with reference to several factors. These included the tensions between an indigenous model of child rearing, which holds that children cannot or will not learn until they are more developed, and a model of child rearing which is advocated through new religious institutions — and therefore linked to moral behavior — in which adults are urged to teach their children. In addition to this, we pointed to the role of schools, closely affiliated with Christian churches, in exposing caregivers to a model which stresses top-down transmission of knowledge, in contrast to actual local practices in which children learn through observation, imitation, trial and error, play, and peer-assisted learning. In interviews, a communicative genre associated with schooling and church because of the direct and 
decontextualized question and answer sequences, adults were able to draw upon idealized western models of cultural transmission to which they are exposed in church and school, to provide the expected answers to questions about their actions. While interlocutors may provide what they perceive to be the answer expected of them through their experience of church, their actual practices of child rearing do not appear to have been altered in any significant way, as indicated in their remarks made in the context of everyday activities.

Although these findings may be taken to suggest that interview data, as used in the study of cultural transmission, is problematic, we instead suggest that interview data has an important place in the study of cultural transmission. As Puri (2013:276) notes, "It is often very difficult to observe actual transmission events or follow individuals for very long to see from whom and how they learn," meaning that cultural transmission can be elusive and needs a robust methodological toolkit to be studied. Rather than problematizing interview data, we contend that interview data is problematic only so long as it serves as the primary method of data collection. As illustrated above in our literature review, interview methods appear particularly limited in the study of cultural transmission, and many of the existing studies relying upon interview data are plagued by significant problems. When interview studies have been used as the primary resources to construct universal theories of learning, particularly by scholars who feel no need to look beyond WEIRD society (e.g., Kruger and Tomasello 1996; Csibra and Gergely 2009; Strimgling et al. 2009; Strauss and Ziv 2004), it is unsurprising that these theories conflict strongly with the ethnographic record.

While a number of scholars acknowledge that processes of cultural transmission need to be investigated cross-culturally, many of these scholars, as we have shown, have relied narrowly upon the problematic use of interview data. To improve the utility of interview data, we suggest that this data must be validated by observing whether what is reported in interviews refers to actual practices of respondents. Beyond the mere triangulation of interview and observational 
data, however, we suggest that both interview and observational data needs to be understood culturally, in light of both local social histories and the role of communication. Bringing all of these sources of information together allows scholars to see how cultural change is unfolding and how it shapes, if at all, practices and how people think and speak about cultural transmission.

We therefore argue that interviews should be situated firmly within an ethnographic framework that provides a grounding in local communicative norms and practices, as well as extensive observational data that not only supplements interview data, but also helps inform and shapes the interview process. As exemplified by a small number of scholars who both acknowledge that cultural transmission is culturally variable and deploy robust methodological toolkits (e.g., Bolin 2006; Rogoff 2014), in bringing these approaches-psychology and anthropology, interview and ethnography_into a more productive relationship, the study of cultural transmission will only be enhanced. 


\section{Notes}

\section{Acknowledgements.}

The research described in this article was supported by the Social Sciences and Humanities Research Council of Canada and approved by Trent University’s Research Ethics Board. This paper was originally presented at the meeting of the Society for Psychological anthropology in 2013. We thank Aude Michelet, Chantal Medaets, and Barbara Polak for their participation in this session, as well as the generous financial support of an anonymous benefactor who facilitated our travel to the conference. Lastly, we thank Ted Lowe, two anonymous reviewers, and Camille Roussel for reading and commenting on this paper.

1 We use the term imitation to refer more precisely to copying where "an observer understands the intentions of the model and takes on this perspective to replicate the model's actions and produce the same result" (Bjorkland and Gardiner 2010:165).

2 By "historically" we are primarily concerned with institutional and social changes that, collectively, are considered to bring about gradual cultural change.

3 Language is certainly a key component of culture. Many contemporary texts continue to assert that parental teaching plays a significant role in language acquisition, in spite of the absence of such instruction in many, if not most, societies (Ochs 2008).

4 See also Cronk $(1993 ; 2000)$ who documents systematic contradictions between interview and observation data, which he attributes to interlocutors relying upon a "traditional" model of behavior to which their own actions do not adhere. 


\section{References Cited}

Arnold, Denise Y.

2006 The Metamorphosis of Heads: Textual Struggles, Education, and Land in the Andes.

Pittsburgh, PA: University of Pittsburgh Press.

Atran, Scott and Dan Sperber

1991 Learning without teaching: Its place in culture. In Culture, Schooling and

Psychological Development. Liliana T. Landsmann, ed. Pp. 39-55. Norwood, NJ: Ablex.

Barth, Frederik

1975 Ritual and Knowledge among the Baktaman of New Guinea. New Haven: Yale University Press.

Bird, Douglas W. and Rebecca Bliege Bird

2005 Martu Children's Hunting Strategies in the Western Desert, Australia. In Hunter

Gatherer Childhoods: Evolutionary, Developmental, and Cultural Perspectives. Barry S.

Hewlett and Michael E. Lamb, eds. Pp. 129-146. New Brunswick, NJ:

Aldine/Transaction.

Bolin, Inge

2006 Growing up in a Culture of Respect: Childrearing in Highland Peru. Austine:

University of Texas Press.

Bjorklund, David F. and Gardiner, Amy K.

2010. Object play and tool use: developmental and evolutionary perspectives. In The Oxford Handbook of Play. Anthony Pellegrini ed. Pp 153-171. New York: Oxford University Press

Bonawitz, Elizabeth, Patrick Shafto, Hyowon, Gweon, Noah D. Goodman, Elizabeth Spelke and Laura Schultz 
2011 The double-edged sword of pedagogy: Instruction limits spontaneous exploration and discovery. Cognition 120:322-330.

Boyette, Adam H.

2013 Social Learning During Middle Childhood among Aka Foragers and Ngandu Farmers of the Central African Republic. Unpublished Ph.D. Dissertation, Washington State University.

Briggs, Charles L.

1986 Learning How to Ask: A Sociolinguistic Appraisal of the Interview in Social Science Research. Cambridge: Cambridge University Press.

Brison, Karen J.

2009 Shifting Conceptions of Self and Society in Fijian Kindergarten. Ethos 37(3):314-333.

Bruner, Jerome

1966 Toward a Theory of Instruction. Cambridge, MA: Harvard University Press.

Bulmer, Ralph

1968 The Strategies of Hunting in New Guinea. Oceania 38(4):302-318.

Carrs, Brian W. and Richard A. Smith

1977 Culture Change and Education at Wankung, Papua New Guinea. Australia and New Zealand Journal of Sociology 13(2):161-168.

Chapin, Bambi L.

2014 Childhood in a Sri Lankan Village: Shaping Hierarchy and Desire. New Jersey:

Rutgers University Press.

Conroy, John D.

1970 The Private Demand for Education in New Guinea: Consumption or Investment. The Economic Record 46(116):497-516.

Cronk, Lee 
1993 Parental Favoritism towards Daughters. American Scientist 81:272-280.

Cronk, Lee

2000 Female-Biased Parental Investment and Growth Performance among the Mukogodo. In Adaptation and Human Behavior: An Anthropological Perspective. Lee Cronk, Napoleon Chagnon, and William Irons, eds. Pp. 203-221. New York, NY: Aldine.

Csibra, Gergely and György Gergely

2009 Natural Pedagogy. Trends in Cognitive Sciences 13(4):148-153.

Dunn, Judy

1988 The Beginnings of Social Understanding. Cambridge, MA: Harvard University Press.

Fiske, Alan

1997 Learning a Culture the Way Informants Do: Observing, Imitating, and Participating. Unpublished Manuscript, University of California-Los Angeles

Garcia, Camilo, Natanael Rivera and Patricia M. Greenfield

2015 The Decline of Cooperation, the Rise of Competition: Developmental Effects of Long-term Social Change in Mexico. International Journal of Psychology. 50: 6-11.

Gergely, György, Katalin Egyed and Ildikó Király

2007 On pedagogy. Developmental Science 10: 139-146.

Goldman, Shelley and Angela Booker

2009 Making Math a Definition of the Situation: Families as Sites for Mathematical

Practices. Anthropology and Education Quarterly 40(4):369-387.

Gosselain, Olivier P.

2008 Mother Bella Was Not a Bella: Inherited and Transformed Traditions in Southwestern

Niger. In Cultural Transmission and Material Culture: Breaking Down Boundaries.

Miriam T. Start, Brenda J. Bowser, and Lee Horne, eds. Pp. 150-177. Tucson, AZ: The

University of Arizona Press. 
Gosselain, Olivier P.

2008 The Cultural Structuring of Children's Play in a Rural African Community. In The Many Faces of Play. Kendall Blanchard, ed. Pp. 96-103. Champaign, IL: Human Kinetics Publishing.

Harrison, Simon

1993 The Mask of War: Violence, Ritual and the Self in Melanesia. Manchester: Manchester University Press.

Hayden, Brian and Aubrey Cannon

1984 Interaction Inferences in Archaeology and Learning Frameworks of the Maya. Journal of Anthropological Archaeology 3:325-367.

Henrich, Joseph and Broesch, James

2011. On the nature of culture transmission networks: Evidence from Fijian villages for adaptive learning biases. Transactions of the Royal Society B 366: 1139-1148.

Hewlett, Barry S. and Luigi L. Cavalli-Sforza

1986 Cultural Transmission among Aka Pygmies. American Anthropologist 88:922-934.

Hewlett, Barry S., Hillary N. Fouts, Adam H. Boyette, and Bonnie Hewlett

2011 Social Learning among Congo Basin Hunter-Gatherers. Philosophical Transactions of the Royal Society: Biology 366:1168-1178.

Hewlett, Bonnie L.

2013 Listen, Here is a Story: Ethnographic Life Narratives from Aka and Ngandu Women of the Congo Basin. New York, NY: Oxford University Press.

Hewlett, Bonnie L. with Barry S. Hewlett

2013 Hunter-Gatherer Adolescence. In Adolescent Identity. Bonnie L. Hewlett, ed. Pp 73101. New York, NY: Routledge.

Howell, Signe 
1988 From Child to Human: Chewong Concepts of Self. In Acquiring Culture: Cross

Cultural Studies in Child Development. Gustav Jahoda and Ioan M. Lewis, eds. Pp. 147168. London, UK: Croom Helm.

Jorgensen, Dan

1981 Taros and Arrows: Order, Entropy, and Religion among the Telefolmin. Ph.D.

Dissertation, Department of Anthropology, University of British Columbia.

Kline, Michelle. A.

2015 How to learn about teaching: An evolutionary framework for the study of teaching behavior in humans and other animals. Behavioral and Brain Sciences. 38, e31 January

Kline, Michelle A., Robert Boyd, and Joseph Henrich

2013 Teaching and the Life History of Cultural Transmission in Fijian Villages. Human Nature 24:351-374.

Konner, Melvin J.

2010 The Evolution of Childhood: Relationships, Emotion, Mind. Cambridge: Belknap Press.

Kruger, Ann C. and Michael Tomasello

1996 Cultural Learning and Learning Culture. In The Handbook of Education and Human Development: New Models of Learning, Teaching, and Schooling. David R. Olson and Nancy Torrance, eds. Pp. 369-387. Cambridge, MA: Blackwell.

Kulick, Don

1992 Language Shift and Cultural Reproduction: Socialization, Self, and Syncretism in a Papua New Guinean Village. Cambridge: Cambridge University Press.

Lancy, David F.

1996 Playing on the Mother Ground: Cultural Routines for Children's Development. New York, NY: Guilford. 
Lancy, David F.

2010 Learning "From Nobody:" The Limited Role of Teaching in Folk Models of Children's Development. Childhood in the Past 3:79-106.

Lancy, David F.

2012 "First You Must Master Pain:" The Nature and Purpose of Apprenticeship Society for the Anthropology of Work Review 33:113-126.

Lancy, David F.

2015 The Anthropology of Childhood: Cherubs, Chattel, Changelings, $2^{\text {nd }}$ edition. Cambridge: Cambridge University Press.

Lancy, David F.

In Pressa Playing with knives: The socialization of Self-Initiated Learners. Child Development.

Lancy, David F. in pressb Teaching: Natural or Cultural? In Evolutionary Perspectives on Education and Child Development. Dan Berch and David Geary, eds. Heidelberg, DE: Springer.

Lancy, David F. and M. Annette Grove

2011 “Getting Noticed:” Middle-Childhood in Cross-Cultural Perspective. Human Nature 22:281-302.

Langdon, Susan 2013 Children as early learners and producers in early Greece. In The Oxford Handbook of Childhood and Education in the Classical World. Judith E .Grubbs, Tim Parkin and Roslynne Bell, eds. Pp. 172-194, Oxford: Oxford University Press.

Lave, Jean 
1988 Cognition in Practice: Mind, Mathematics and Culture in Everyday Life.

Cambridge: Cambridge University Press.

Lave, Jean and Etienne Wenger

1991 Situated Learning: Legitimate Peripheral Participation. Cambridge: Cambridge University Press.

LeVine, Robert A., Sarah LeVine, Beatrice Schnell-Anzola, Meredith L. Rowe, and Emily

Dexter

2012 Literacy and Mothering: How Women's Schooling Changes the Lives of the World's Children. New York, NY: Oxford University Press.

Liebenberg, Louis

1990 The Art of Tracking. Cape Town, South Africa: Creda Press.

Little, Christopher A. J. L.

2011 How Asabano Children Learn; or, Formal Schools amongst Informal Learners. Oceania 81(2):148-166.

Marlowe, Frank

2010 The Hadza: Hunter-Gatherers of Tanzania. Berkeley, CA: University of California Press.

Mead, Margaret

1964 Continuities in Cultural Evolution. New Haven, CT: Yale University Press.

Ninnes, Peter M.

1995 Informal Learning Contexts in Solomon Islands and their Implications for the Cross-

Cultural Classroom. International Journal of Educational Development 15(1):15-26.

Ochs, Elinor E.

2008 Learning from a Language Socialization Perspective. Invited paper presented at

Symposium: Collaboration in the Study of Childhood: Anthropological Perspectives on 
Learning. American Anthropological Association Annual Meeting, San Francisco, November.

Odden, Harold L. and Philippe Rochat

2004 Observational Learning and Enculturation. Education and Child Development 21(2):39-50

Odden, Harold L.

2007 The Acquisition of Cultural Knowledge of Hierarchy by Samoan Children.

Unpublished Ph.D. dissertation, Emory University.

Peters, John F.

1998 Life among the Yanomami: The Story of Change among the Xilixana on the Mucajai River in Brazil. Orchard Park, NY: Broadview Press.

Prout, Allen

2003 Participation, Policy, and the Changing Conditions of Childhood. In Hearing the Voices of Children. Christine Hallett and Allen Prout, eds. Pp. 11-25. London:

Routledge.

Puri, Rajindra K.

2013 Transmitting Penan Basketry Knowledge and Practice. In Understanding Cultural Transmission: A Critical Anthropological Synthesis. Roy Ellen, Stephen J. Lycett, and Sarah E. Johns, eds. Pp. 266-299.Oxford: Berghahn Books.

Qvortrup, Jens

1990 A Voice for Children in Statistical and Social Accounting: A Plea for Children's Right to be Heard. In Constructing and Deconstructing Childhood: Contemporary Issues in the Sociological Study of Childhood. Allison James and Allen Prout, eds. Pp. 78-98. New York, NY: The Falmer Press.

Raum, Otto F. 
1940 Chaga Childhood. Oxford: Oxford University Press.

Reyes-Garcia, Victoria, James Broesch, and TAPS Bolivian Study Team

2013 The Transmission of Ethnobotanical Knowledge and Skills among Tsimane' in the Bolivian Amazon. In Understanding Cultural Transmission in Anthropology. Roy Ellen, Stephen J. Lycett, and Sarah E. Johns, eds.. Pp. 181-212. Oxford: Berghahn.

Rival, Laura M.

2000 Formal Schooling and the Production of Modern Citizens in the Ecuadorian Amazon. In Schooling the Symbolic Animal: Social and Cultural Dimensions of Education. Bradley A.U. Levinson, ed... Pp. 108-122. Lanham, MD: Rowman \& Littlefield.

Robbins, Joel

2004 Becoming Sinners: Christianity and Moral Torment in a Papua New Guinean Society. Berkeley: University of California Press.

Rogoff, Barbara

1981. Adults and Peers as Agents of Socialization: A Highland Guatemalan Profile. Ethos, 9(1):18-36.

Rogoff , Barbara

2014. Learning by observing and pitching in to family and community endeavors: An orientation. Human Development, 57: 69-81.

Rogoff, Barbara, Maricela Correa-Chávez and Marta N. Cotuc 2005. A cultural/historical view of schooling in human development. In David B. Pillemer and Sheldon H. White (Eds.), Developmental Psychology and Social Change: Research, History, and Policy. pp. 225-263. Cambridge: Cambridge University Press.

Rogoff, Barbara, Behnosh Najafi, and Rebeca Mejía-Arauz

2014. Constellations of cultural practices across generations: Indigenous American Heritage and Learning by Observing and Pitching in. Human Development 57:82-95 
Rogoff, Barbara, Ruth Paradise, Rebeca M. Arauz, Maricela Correa-Chávez, and Cathy

Angelillo

2003 Firsthand Learning through Intent Participation. Annual Review of Psychology 54:175-203.

Stewart, Pamela and Andrew Strathern

2000 Body and Mind in Mount Hagen, Highlands Papua New Guinea. Anthropology of Consciousness 11(3-4):25-39.

Strauss, Sidney and Margalit Ziv

2004. Teaching: ontogenesis, culture, and education. Cognitive Development. 19:451-456.

Strimling, Pontus, Magnus Enquist, and Kimmo Eriksson

2009 Repeated Learning Makes Cultural Evolution Unique. Proceedings of the National Academy of Sciences of the United States of America 106:13870-13874.

Thornton, Alex and Nichola J. Raihani

2008 The Evolution of Teaching. Animal Behaviour 75:1823-1836.

Tomasello, Michael

2001 Cultural Transmission: A View from Chimpanzees and Human Infants. Journal of Cross-Cultural Psychology 32(2):135-146.

Urrieta, Luis, Jr.

2016 Pitching-In and the connections to Native and Indigenous Knowledge Systems. In Advances in Child Development and Behavior. Maricela Correa-Chavez, Rebeca MejiaArauz, Barbara Rogoff eds Pp.357-379. Oxford: Elsevier

Whiting, Beatrice B. and John W. M. Whiting

1975 Children of Six Cultures: A Psycho-Cultural Analysis. Cambridge, MA: Harvard University Press. 
